\title{
THE ROLE OF GENDER AND STATUS IN COMMUNICATION BETWEEN DOCTORS AND PATIENTS IN MALAYSIAN CONTEXTS
}

\section{Leila Mohajer* and Noraida Endut}

Centre for Research on Women and Gender (KANITA), Universiti Sains Malaysia, Pulau Pinang, MALAYSIA

*Corresponding author: leilamohajer7@gmail.com

Published online: 15 April 2020

To cite this article: Leila Mohajer and Noraida Endut. 2020. The role of gender and status in communication between doctors and patients in Malaysian contexts. Kajian Malaysia 38(Supp.1): 89-108. https://doi.org/10.21315/km2020.38.s1.6

To link to this article: $\mathrm{https} / /$ doi.org/10.21315/km2020.38.s1.6

\begin{abstract}
This study investigates the ways in which gender and status of doctors and patients influence the effectiveness of communication in sustainable health development among Malaysians. In order to conduct this research, we look at the interruption patterns in doctor-patient interaction because interruption provides an opportunity for interactants to dominate the conversation which can have negative effects on the treatment and consultation process. The data consists of 480 minutes of recorded conversations between doctors and patients of both genders during 160 consultation visits. We have used both quantitative and qualitative methods to analyse our data. Conversation analysis has also been used to evaluate the linguistic elements in their talk. The findings indicate that the gender of the interactants has effects on the interruption they make. It appears that male interactants in this study, regardless of their status as a doctor or patient, have the tendency to make intrusive interruptions more than female interactants. In addition, the status of the interactants was a determining factor in the interruption process. Doctors, holding a higher status at the time of consultation, made more intrusive interruptions and patients made more cooperative interruptions. However, based on the analysis, male doctors were more cooperative with their male patients than with their female patients which indicate that male doctors practised discrimination unintentionally. On the other hand, female doctors treated patients of both genders in the same manner. Based on our findings, listening skills and communication training for doctors can minimise miscommunication during consultation visits
\end{abstract}


and enhance healthcare quality which ultimately assists to achieve sustainable health development goals.

Keywords: doctor-patient conversation, gender, status, interruptions, sustainable health development goals

\section{INTRODUCTION}

Communication through speaking is considered a vital component of social interaction in various social settings. Doctor-patient spoken interaction is an area which is not paid adequate attention in the Malaysian context, despite its significance. According to Willes and Allen (2014), "the doctor/patient interaction lies at the heart of the practice of medicine" (p. 9). Accordingly, improving the quality of the interaction between doctors and patients has major benefits for both parties in the treatment process (Fritzsche et al. 2014) and in decreasing healthcare delivery impotence (Belasen and Belasen 2018).

As can be perceived, it is very important for doctors and patients to have effective communication. However, research shows that doctors treat and give advice to women and men differently (Anderson et al. 2012) and that female and male doctors adopt different linguistic strategies to treat their patients according to their genders (West 1998; 2011). This asymmetrical behaviour existing among them will definitely affect the communication between doctors and patients (Franks and Bertakis 2003; Hall et al. 1994; Kaplan et al. 1995) which can ultimately lead to the failure of their treatment or create some misunderstandings.

Moreover, the unequal social status between doctors and patients can have diverse effects on doctors' practice. According to Litosseliti (2014), "social interaction is influenced by a social hierarchy" (p. 40). This social asymmetry can grant doctors to be in a higher position and that affects their language as well (West 2011). In this regard, West (2011) asserts "patients' situational dependency on physicians, physicians' professional prestige and their authority over patients all ensure physicians the necessary leverage for controlling interpersonal encounters" (p. 473). Nevertheless, according to Sustainable Development Goal (SDG) No. 3, the main aim is to ensure healthy lives and promote well-being for all at all ages without any discrimination and that includes gender and status as well.

The asymmetrical interaction which exists between doctors and patients based on the above studies can influence sustainable health development goals that Malaysia is attempting to achieve in order to create a healthier society. Therefore, this study would shed light on understanding the role of interaction between doctors and patients. 


\section{INTERRUPTIONS}

Interruptions are categorised as any deep intrusions into the boundaries of a unit type according to Zimmerman and West (1975). Unit type is a meaningful end of the current speaker's speech prior to the lexical elements which could be considered the termination of a unit type. Interruptions are regarded as intrusions since they infringe the current speaker's turn and natural flow of speech (Zimmerman and West 1975). This is driven from a model of turn taking conversation pioneered by Sacks, Schegloff and Jefferson (1974) who believed that one speaker at a time is the preferred pattern. According to them, the second speaker who intends to take a turn must pay attention to the "unit type" in the current speaker's speech. If the second speaker does not consider termination of a unit type, then the interruption occurs. Thus, according to them, a turn should start at transition relevance place (TRP), which is the termination of a unit type because at this point the speakers' utterance is complete in terms of grammar and meaning. Coates (2011) however, asserts that the rule of one speaker at a time that Sacks, Schegloff and Jefferson (1974) have proposed is not viable in non-dyadic conversation and cannot be applied in every interaction. Elsewhere, she mentions that this rule is more applicable to the all-men conversation (Coates 2004).

It is also believed that not all the interruptions are intrusive and that they can be cooperative too (Coates 2011; Zhao and Gantz 2003). Zhao and Gantz (2003) proposed two kinds of interruptions, disruptive and cooperative interruptions, based on the purposes that they imply. In cooperative interruptions, interactants interrupt in order to show their support, agreement and also to ask for further explanation and clarification. On the other hand, disruptive interruptions include disagreements, rejections and also the control of the interaction. Therefore, unlike cooperative interruptions which have positive effects, they have negative effects on interpersonal relationships between the interactants and endorse a sense of power and dominance. However, the ways that interruptions are interpreted in a context and different social settings between the interactants determine whether they are considered intrusive or cooperative since interruption is multifunctional. In the same way, James and Clarke (1993) assert that "the extent to which an interruption is interpreted as negative and disruptive is probably not a black-andwhite matter, but rather a matter of degree" (p. 241). In this article, we look at both intrusive and cooperative interruptions that doctors and patients make. We also consider the gender and status of doctors and patients because these two elements play an important role in the process of turn taking. 


\section{INTERRUPTION AND GENDER}

In the domain of sociolinguistics, it is believed that women and men interact and communicate differently in same sex and opposite sex groups (Maltz and Borker 2011). The linguistic elements can generate different functions for women and men in an interaction. Men tend to dominate women in conversation (LeetPellegrini 1980; Fishman 1980, 1983; Zimmerman and West 1975), induce their power via language and tend to preserve their masculinity (Coates 2004; Tannen 1994). Therefore, women face interruptions more than men (Blair-Loy et al. 2017) while they try to support, cooperate and maintain solidarity throughout their talk (Coates 2004). In other words, women relinquish the floor without any serious complaints in response to males' interruptions and domination (Holmes 2008). Men, on the other hand, control the conversation by keeping the floor and talking more (Herring, Johnson and DiBenedetto 2011).

Men are believed to interrupt at a higher rate compared to women (Peterson 1986; Zimmerman and West 1975). It is mainly due to the fact that interruption provides an opportunity for men to exert their power (Coates 2004).

Conversely, in single-sex conversations the case is different. It has been found that females have more numbers of interruptions compared to the males in the process of taking turns. Women tend to interrupt other women more than men interrupting other men (Street Jr and Murphy 1987; Bilous and Krauss 1988; Mohajer 2006). Tannen (2005) suggests that some speakers express their solidarity and interest in the others' speech through overlaps and latching of utterances.

\section{INTERRUPTION AND DOCTOR-PATIENT INTERACTION}

In doctor-patient interactions, it is believed that the physicians interrupt their patients' statements more than the reverse in order to direct questions towards a specific concern (Beckman and Frankel 1984). In other words, they do not let their patients fully explain their problems. They try to control the amount of information which is elicited from the patients especially in the beginning of the clinical encounter. According to Beckman and Frankel (1984), this controlled style of interaction can result in early interruption of patients which in the end will lead to poor communication where some important information did not have the opportunity to be said.

It is believed that there is an asymmetry in healthcare communication (Heritage and Sefi 1992; Peräkylä 2002). Being a doctor places them in a higher position than the patients and that creates a kind of power imbalance where doctors are more in power and control. That provides an opportunity for 
doctors to interrupt patients more than the reverse. According to Li et al. (2004), the difference between doctors and patients lies in the type of interruption rather than the number of interruptions that they make. In their study, doctors made more intrusive interruptions while patients made more cooperative interruptions.

As we discussed earlier, men tend to interrupt women more in different social settings and clinical setting is not an exception. In doctor-patient communication, men tend to interrupt women more regardless of being doctors or patients (West 2011). Moreover, male physicians made more intrusive interruptions when their patient was a female ( $\mathrm{Li}$ et al. 2004). This will place female patients in a position that they are not able to state all their problems and can ultimately lead to failure of high-quality treatment. Moreover, another study found that patients had a better experience with a female doctor than a male doctor when it involved shared decision-making (Tates et al. 2017). In other words, female doctors created a more comfortable environment for patients than male doctors to open up and make health decisions cooperatively.

There are not many studies on doctor-patient interaction in the Malaysian context to focus on the role of language on treatment and healthcare quality. Therefore, there is a gap to be filled in the Malaysian context. The research enables us to go through the details of doctor-patient interaction in terms of interruption patterns. The linguistic behaviour of doctors based on their gender and status can affect the treatment process positively or negatively. This may even lead to unequal healthcare attention that patients receive based on their gender and status. This is a kind of discrimination which is not in line with sustainable health development goals in Malaysian society. As a result, this study aims to look at the linguistic behaviour that exists between doctors and patients in the culture of Malaysian contexts, specifically in medical practice rooms of Penang Island. This study is going to focus on the interruptive behaviour of doctors and patients. In this research, gender is considered in every step of analysis in order to explore its impact on doctor-patient communications.

\section{THE PRESENT STUDY}

\section{Participants}

Participants in this study are both doctors and patients. The most important element that we considered when selecting the participants was their gender. The other element was the nationality of the participants. Since this study is in the Malaysian context, the participants needed to be Malaysians of any ethnical background. 
The data is collected from 2 female and 2 male doctors with 20 male and 20 female patients for each doctor. Therefore, there are 2 female doctors with 40 female patients and 40 male patients. Also, 2 male doctors with 40 female patients and 40 male patients.

\section{Materials}

The material for this study is the transcribed recorded conversation which naturally occurred between doctors and patients during consultation visits. Drew's transcription convention (2014) is adapted and used in the present study (see Appendix). The conversation between doctors and patients in this study can be considered naturally occurred interaction because the subjects were neither aware of the nature of the study nor the interruption which is the core element of analysis. However, they were all aware that their interaction was being recorded.

The interactions between doctors and patients were in either Malay or English. All Malay interactions are then translated into English and placed in double parentheses in italics under the original utterances. The other languages that Malaysians speak such as Tamil and Chinese were not spoken during the visits that we recorded.

For this research, we have recorded 160 doctor-patient encounters and that generates 480 minutes of recordings. Due to the comparison that we need to make between encounters based on the participants' gender, we tried to select the equal amount of recorded conversation for each group of doctor-patient dyads.

\section{Methodology/Analytical Framework}

Conversation analysis (CA) is considered to be a prominent method of analysing medical communication and interaction (Heritage and Maynard 2006). In this study, CA is used to analyse the instances of both types of intrusive and cooperative interruptions exchanged between doctors and patients in a clinical setting. In order to analyse interruptions, the focus is on turn taking process and how intrusive and cooperative the instances are according to Sacks, Schegloff and Jefferson's (1974) interruption model. In this study, a mixture of both qualitative and quantitative approaches is used. The frequency counts of interruptions and their types based on the participants' gender and status are analysed quantitatively. Then, in order to observe the influence of gender and status, qualitative analysis is applied. As such, this study benefits from both approaches on its own accord. 


\section{Procedure}

Before collecting data, this study has successfully gone through an intensive ethical clearance procedure. In the clinic, the researchers and their assistants coordinated with doctors and nurses in advance. Dyadic encounters between doctors and patients are recorded in doctors' practice rooms. In order to do that, a professional voice recorder is placed in the doctor's office and their conversation is recorded while they are communicating. The participants were all aware of the presence of the recorder. Both doctors and patients were informed about the study and recording process and they gave their written consent as well. The recording is done during consultation only and when the doctors and patients are in the examination room, the recording is stopped, and the researcher is not allowed to enter the examination room.

\section{DATA ANALYSIS}

Each instance is analysed within its individual dyadic interaction based on gender and status of doctors and patients. Next, findings are used to compare and discuss the instances. After the comparison, any similarities or differences would be considered in order to present comprehensive findings. Both qualitative and quantitative approaches are used at this stage. As discussed earlier, quantitative analysis is employed to determine the number and types of interruption that each party makes. Afterwards, the qualitative analysis explains the instances with respect to the gender and status of the interactants.

\section{Interruption between Doctors and Patients}

Interruptions between doctors and patients have been divided into two main sections, intrusive and cooperative. Then, each section is divided into two sections based on doctors' and patients' gender.

\section{Intrusive interruption among doctors and patients}

Intrusive interruption occurs when the interrupter barges in before the speaker has completed a unit type. This is called intrusive because the interrupter did not pay attention to the completeness of the speaker's sentence. Moreover, he has violated the flow of talk and did not let the current speaker complete his sentence. As such, this is an indication of dominance in an interaction. 
Our data illustrates that doctors, irrespective of their gender, interrupt their patients more than the reverse. In other words, their status as a doctor creates an authoritative role for them to make intrusive interruptions and dominate the conversation. Therefore, we can argue that status is an effective factor which gives doctors the opportunity to overpower their patients in conversation.

Table 1: Intrusive interruptions among doctors and patients in dyadic interactions

\begin{tabular}{lccc}
\hline Dyads & Doctor & Patient & Total \\
\hline $\begin{array}{l}\text { Female doctor } \\
\text { Female patient }\end{array}$ & 52 & 47 & 99 \\
$\begin{array}{l}\text { Female doctor } \\
\text { Male patient }\end{array}$ & 58 & 83 & 141 \\
$\begin{array}{l}\text { Male doctor } \\
\text { Female patient }\end{array}$ & 39 & 30 & 69 \\
$\begin{array}{l}\text { Male doctor } \\
\text { Male patient }\end{array}$ & 49 & 27 & 76 \\
\hline Total & 198 & 187 & 385 \\
\hline
\end{tabular}

There is one significant exception where male patients interrupted the female doctors at a very significant frequency. The occurrence of intrusive interruption is much higher in dyads when the doctor is female than when the doctor is male (Table 1). Table 1 shows that doctors interrupt their patients in same-sex dyads more than in cross-sex dyads. In addition, male doctors interrupt significantly more in same-sex dyads. It shows that gender has a direct effect on the number of intrusive interruptions made by doctors and patients.

\section{a. Intrusive interruptions among female doctors and patients of both genders}

Based on the analysis, female doctors interrupt female patients slightly more than the reverse which is not significant as illustrated in Table 2. Nevertheless, when a patient is a man, he interrupts female doctors at a very high level. Male patients interrupted female doctors 83 times while the female doctors interrupted them only 58 times. 
Table 2: Intrusive interruptions among female doctors and patients of both genders

\begin{tabular}{lccc}
\hline Dyads & Doctor & Patient & Total \\
\hline $\begin{array}{l}\text { Female doctor } \\
\text { Female patient }\end{array}$ & 52 & & 99 \\
$\begin{array}{l}\text { Female doctor } \\
\text { Male patient }\end{array}$ & 58 & & \\
\hline Total & 110 & 130 & 240 \\
\hline
\end{tabular}

As can be seen in Table 2, the number of interruption increases considerably when the patient is male with 141 instances. Male patients interrupt to assert their own ideas and divert the flow of talk as shown in the following excerpt.

\section{Excerpt 1 (female doctor-male patient)}

[1] D: Diaorang nak tengok rekod perubatan awak, sekurang-kurangnya, ada suratlah, daripada sana mengatakan apa yang diaorang telah buat. Apa // ((...want to see your medical records, at least, a medical referral letter, that indicates the history of your medical treatment. What //))

[2] M: // Kalau ada ubat pun macam, mula-mula je, mula-mula saya check tu, dekat klinik, ubat tu yang dia bagi, ubat tahan sakit dengan ubat tahan sakit (.) Antibiotik biasa. ((// If there is any medication, it was just after the first medical examination in the beginning when doctors gave me two types of pain killers (.) The usual antibiotics))

Excerpt 1 illustrates how the male patient interrupts the female doctor before she finishes her sentence. It appears that the doctor wants to ask another question but immediately after she utters the question word "what", the patient barges in and does not let her continue. This is an indication of intrusion where the patient does not pay attention to the completeness of the doctor's utterance. The male patient in this instance appears dominant and intruding.

\section{Excerpt 2 (female doctor-male patient)}

[3] M: So now, my other complaint is here and my neck [whole thing here pain].

[4] D: [Aha] (xxx) how many days now?

[5] M: Quite sometimes, about a month, I think.

[6] D: Uhm [is there any difficulty?]

[7] M: [So, is there any way] to do the scanning? 
In line [6], the doctor tries to ask a question for more clarity but immediately the male patient interrupts her in line [7] to suggest a diagnosis tool to the doctor without paying attention to the termination of her utterance. This shows the interrupter's inattentiveness to the current speaker's right. In addition, it indicates that the patient dominates the conversation not only by ignoring the doctor's question but also by diverting the conversation towards the question that he is asking.

In general, the conversations between female doctors and male patients are laden with intrusive interruptions which indicate that gender is an effective factor in this dyadic interaction. It also shows that the control and power that doctors hold during the patients' visits are less observed when the patient is a male. In other words, male patients show more dominance while talking to female doctors regardless of the higher status and the relative power that women hold as doctors.

\section{b. Intrusive interruptions among male doctors and patients of both genders}

Table 3 demonstrates the frequency counts of intrusive interruptions made by male doctors and both female and male patients.

Table 3: Intrusive interruptions among male doctors and patients of both genders

\begin{tabular}{lccc}
\hline Dyads & Doctor & Patient & Total \\
\hline $\begin{array}{l}\text { Male doctor } \\
\text { Female patient }\end{array}$ & 39 & 30 & 69 \\
$\begin{array}{l}\text { Male doctor } \\
\text { Male patient }\end{array}$ & 49 & 27 & 76 \\
\hline Total & & 57 & 145 \\
\hline
\end{tabular}

It appears that male doctors interrupted their patients more than the reverse. Male doctors interrupted their female patients 39 times while female patients interrupted male doctors 30 times. However, as can be seen in Table 3, male doctors interrupted male patients at a significantly higher rate. They interrupt their male patients 49 times which is almost double the number that male patients interrupt male doctors at 27 .

Although the interruptions that male doctors make may appear intrusive, they are not intrusive when their patient is a man. The interruptions mainly occur to ask a follow-up question or clarify an ambiguity as shown in Excerpt 3. 


\section{Excerpt 3 (male doctor-male patient)}

[8] D: Folic acid also, any vitamin C?

[9] M: Ya two, one (xxx) one, uuh //

[10] D: // Small one?

[11] M: Small one

[12] D: Small one I think you should stop

Excerpt 3 demonstrates that in line [9], the male patient tries to remember the type or number of the pills. Therefore, at the end of his utterance, he appears hesitant and tries to buy some time to remember it "ya two, one (xxx) one, uuh". At this point, the doctor finds an opportunity to interrupt him before his utterance is complete in order to ask about the size of the pills in line [10]. Further down in line [12], the doctor explains more about this issue. Although the male doctor's interruption appears intrusive, it was projected for more clarity. There is no indication of dominance or power demonstration.

Nevertheless, it seems that during the interaction between male doctors and female patients, the interruptions that male doctors make have traces of intrusiveness and ultimately denotes power as shown in Excerpt 4.

\section{Excerpt 4 (male doctor-female patient)}

[13] D: No breathing difficulty?

[14] F: No, only itchiness

[15] D: (xxx)

[16] F: Also, but that's only moisture

[17] D: Other options, we are doing the injection

[18] F: Itchiness [so long]

[19] D: [Injection] will reduce the (itchiness) actually

Excerpt 4 demonstrates how male doctor interrupts his female patient. In line [14], the female patient emphasises that the only issue she has is itchiness and the male doctor replies in line [17] that injection is the solution. However, the patient does not consider doctor's reply and talks about itchiness again in line [18] but this time her utterance is overlapped and ultimately interrupted by the doctor's comment in line [19] to stress that "injection will reduce the itchiness actually". In this example, the doctor's interruption appears powerful because his suggestion was not considered by the patient in the first place and then in line [19] he interrupts to assert his idea. This is an example of a power play between male doctors and female patients. Excerpt 5 displays another instance. 


\section{Excerpt 5 (male doctor-female patient)}

[20] F: Haa, dia muntah sekali, ini cirit sekali ((yes, he vomited once and had diarrhoea once))

[21] D: Hmm ((hmm))

[22] F: Dia yang start first lah. Dia // ((he was the one who started first. He))//

[23] D: // Ada daging? nasi arab? ((had meat? Arab rice?))

[24] F: Ada ayam ((had chicken))

The male doctor in Excerpt 5, interrupts his female patient in line [23] to ask a question and receive more information about the patient's situation. Although this interruption is for the purpose of seeking information which is necessary for doctors, it has traces of power and dominance, because the male doctor interrupts his patient's flow of talk without letting her finish her sentence. Moreover, by asking a question in line [23], he diverts the conversation path towards his own direction. This can be an indication of male doctors' power demonstration towards female patients. In general, male doctors are more dominant when their patient is female.

\section{Cooperative interruptions among doctors and patients}

Cooperative interruption refers to the overlaps which occur when the interrupter tries to interrupt at the end of the current speaker's unit type. The interrupter, assuming that the current speaker has completed his/her sentence, self-selects him/ her to take a turn. However, it seems that the current speaker attempts to continue speaking; therefore, overlaps between utterances occur. This type of interruption is not considered intrusive and the interrupter usually tries to either add something to the conversation or elaborate more.

Table 4: Cooperative interruptions among doctors and patients in dyadic interactions

\begin{tabular}{lccc}
\hline Dyads & Doctor & Patient & Total \\
\hline $\begin{array}{l}\text { Female doctor } \\
\text { Female patient }\end{array}$ & 22 & 40 & 62 \\
$\begin{array}{l}\text { Female doctor } \\
\text { Male patient }\end{array}$ & 22 & 31 & 53 \\
$\begin{array}{l}\text { Male doctor } \\
\text { Female patient }\end{array}$ & 16 & 31 & 47 \\
$\begin{array}{l}\text { Male doctor } \\
\text { Male patient }\end{array}$ & 21 & 12 & 33 \\
\hline Total & 81 & 114 & 195 \\
\hline
\end{tabular}


The data demonstrate that patients make more cooperative interruptions compared to doctors in general. There is, however, an exception when male doctors made more cooperative interruptions while interacting with male patients. Moreover, female doctors overlap cooperatively more than male doctors.

\section{a. Cooperative interruptions among female doctors and patients of both genders}

Table 5 shows that patients, regardless of their gender, make more cooperative interruptions than female doctors. They interrupt doctors to show their attentiveness and confirm doctors' comments. This can illustrate that having a subordinate status as a patient makes them more cooperative in that sense.

Table 5: Cooperative interruptions among female doctors and patients of both genders

\begin{tabular}{lccc}
\hline Dyads & Doctor & Patient & Total \\
\hline Female doctor & 22 & 40 & 62 \\
Female patient & & & 53 \\
$\begin{array}{l}\text { Female doctor } \\
\text { Male patient }\end{array}$ & 22 & 31 & 115 \\
\hline Total & 44 & 71 & 53 \\
\hline
\end{tabular}

However, it appears that female patients are more cooperative than male patients. It shows that the gender of the patients is an effective factor in the number of cooperative interruptions that they made. Female patients made cooperative interruptions to show their agreement or understanding more than male patients. The following example shows how a female doctor and a female patient exchange turns cooperatively.

\section{Excerpt 6 (female doctor-female patient)}

[25] D: Semalam you jatuh kena dekat jalan ke? Kaki you tu yang luka tu? Kena dekat jalan raya tak? [on the road ke?] ((Yesterday you fell on the road? Is this the leg that hurts? Did you hit the surface of the road? [on the road?]))

[26] F: [Haa] itu bus station dekat padang kawad sana (([haa] it was at the bus station near the field there))

[27] D: Okay, dekat jalan lah? ((okay, on the road?))

[28] F: Haa, jalan raya ((haa, on the road))

[29] D: Ada kena dekat tanah ke? ((hit the surface(soil)?))

[30] F: Tanah kot. Tembok tembok macam tu ((Surface there. Bumpy like that)) 
In this excerpt, the female doctor asks several questions one after one another in line [25] in order to understand what exactly has happened to the patient. In the following line [26], the female patient assuming that the doctor has asked all the questions, overlaps and tries to reply to the doctor's questions. Here, the patient's reply overlaps with the doctor's utterance. Although the doctor's utterance is complete, it appears that she wants to continue her questions and therefore, their utterances overlap. Although an overlap is considered a type of interruption, in this example it is inferred that this is a cooperative interruption. It is mainly because the interrupter has paid attention to the end of the current speaker's unit type and within the overlap that she tries to answer the questions. After this instance of cooperative overlap, the turns are changed smoothly between the female doctor and the female patient. They are both attentive to the completeness of the current speaker's utterances before they take a turn. As a result, the turns are smoothly exchanged between them and there is no sign of struggle for turns.

\section{b. Cooperative interruptions among male doctors and patients of both genders}

Table 6 demonstrates that patients make more cooperative interruptions compared to male doctors. In other words, patients are more cooperative than male doctors. This is in line with the previous section when the doctor was a female. Therefore, as discussed, the status of the interactants have a direct influence on making cooperative interruptions. The higher the status, the lower are cooperative interruptions.

The data also show that female patients tend to display cooperative attitudes when interacting with men. Male doctors, on the other hand, make more cooperative interruptions when interacting with male patients than with the female patients. Male doctors tend to be more cooperative with patients of their own gender.

Table 6: Cooperative interruptions among male doctors and patients of both genders

\begin{tabular}{lccc}
\hline Dyads & Doctor & Patient & Total \\
\hline $\begin{array}{l}\text { Male doctor } \\
\text { Female patient }\end{array}$ & 16 & 31 & 47 \\
$\begin{array}{l}\text { Male doctor } \\
\text { Male patient }\end{array}$ & 21 & 12 & 33 \\
\hline Total & 37 & 43 & 80 \\
\hline
\end{tabular}


The cooperative interruption that male doctors make when interacting with female patients have pale traces of power and domination as shown in the following excerpt.

\section{Excerpt 7 (male doctor-female patient)}

[31] F: And then, yesterday, dia macam nampak letihlah, dia, apa, tapi dia cirit dua kali je, eh tiga kali [yesterday] ((And then, yesterday, he looked kind of tired, he, what, but he had diarrhoea twice, eh three times [yesterday]))

[32] D: [okay today?]

In line [31], the female patient is describing her son's situation yesterday and doctor overlaps in line [32] to change the direction of the conversation and receive the information that he desires to know. This is an indication of power demonstration where the doctor's gender and status give him the power to interrupt, lead and change the direction of the conversation.

\section{DISCUSSION}

Based on the above analysis, it appears that females are more cooperative than males irrespective of their status as being either doctors or patients. Females listen attentively and interrupt at the point that the current speakers' utterance is complete. The interruptions that they make are laden with attentiveness, support and collaboration. While, on the other hand, male doctors and patients intruded and invaded the flow of talk more than females did. They interrupt when the current speaker is still talking and making a point. In our data, when a male is present, the conversation is loaded with intrusive overlaps where the current speaker had to surrender to his/her male counterpart. This is an indication of power imbalance in female and male conversation which makes gender an effective factor in the number of interruptions as well as interruption types.

When males have tendencies to dominate the conversation in a doctorpatient setting, this can lead to some complications because if females, either a doctor or patient, are not given a proper time to talk, then it can lead to poor treatment. When female doctors are frequently interrupted by male patients, then they are not able to deliver their consultation and advice clearly. Also, if male doctors keep interrupting female patients and do not give them sufficient time to describe their health problems, the patients are not able to receive a satisfactory consultation and it can result in poor treatment and patients' dissatisfaction. These are very important factors in improving and maintaining health development. 
Moreover, the analysis reveals that the status of interactants plays an important role in the interruption process. Being a doctor places them in a higher position than patients, therefore, they make more intrusive and less cooperative interruptions. Except at times, that doctor was a female and patient was a male, making gender a more dominant factor than status. Also, as mentioned earlier, male doctors are very attentive to their male patients and interrupt them cooperatively to show their concentration and support.

\section{CONCLUSION AND IMPLICATIONS}

Sustainable health development aims to create an environment to ensure the wellbeing of society members free of any discrimination. Malaysia tries to set its goals in line with SDG and this article shows that in order to ensure the sustainability of a goal, we need to look at different aspects of an issue. This article discusses that status of doctors and the gender of the interactants are two factors which can affect the consultation process.

Based on our findings, doctors keep interrupting their patients due to the power that they possess as doctors. This can also lead to a treatment which is not in line with sustainable health development goals. Without any discrimination, patients should be given ample time to ask questions and receive satisfactory consultation and healthcare support. They should not feel that they were dominated by their doctors and were not able to talk about their health issues to a satisfactory level.

Therefore, this study argues that providing training courses for doctors would make communication easier for both doctors and patients. There should be a continuing structured strategy to provide doctors with the necessary skills and knowledge to consider sustainable health development goals while communicating with their patients. Doctors should be trained linguistically to consider patients' right to speak and ask questions. In addition, they should be aware of the effect of gender as a determining factor in their communication and treatment process. Having effective communication will create a more comfortable environment for patients to open up and receive a satisfactory consultation which will help improve public health in the long term. Moreover, improving public health and delivering high-quality healthcare will move society towards a sustainable healthcare system.

\section{ACKNOWLEDGEMENTS}

This research was funded by a Short-term Grant No: 304/PKANITA/6313189 from Universiti Sains Malaysia. 


\section{APPENDIX}

\section{Transcription Convention}

\begin{tabular}{ll}
\hline[ & A single left bracket indicates the point of overlap onset. \\
\hline$]$ & A single right bracket indicates the end of the overlapped utterance. \\
\hline$?$ & Question marks show a question or the rising tone which signifies a question. \\
\hline$/(\mathrm{xxx})$ & Three xs in single parenthesis indicate unintelligible speech. \\
\hline$()$. & $\begin{array}{l}\text { Double slashes, one at the end of one line and one at the beginning of a next } \\
\text { line indicate an interruption without any simultaneous speech. }\end{array}$ \\
\hline$(($ word $))$ & A dot in parenthesis indicates a long pause - more than one second. \\
\hline$[1],[2]$ & Translation of utterances are in italics and placed in double parentheses. \\
\hline $\begin{array}{l}\text { Capital letters } \\
\text { in square } \\
\text { brackets }\end{array}$ & $\begin{array}{l}\text { Arabic numerals in square brackets indicate the lines of the transcription from } \\
\text { the beginning of each transcription. }\end{array}$ \\
\hline
\end{tabular}




\section{REFERENCES}

Anderson, C., C.B. Peterson, L. Fletcher, J.E. Mitchell, P. Thuras and S.J. Crow. 2012. Weight loss and gender: An examination of physician attitudes. Obesity Research 9(4): 257-263. https://doi.org/10.1038/oby.2001.30

Beckman, H.B. and R.M. Frankel. 1984. The effect of physician behavior on the collection of data. Annals of Internal Medicine 101(5): 692-696. https://doi.org/10.7326/00034819-101-5-692

Belasen, A.R. and A.T. Belasen. 2018. Dual effects of improving doctor-patient communication: Patient satisfaction and hospital ratings. https://scholar.google. com/scholar?cluster $=14327715133074689875 \& \mathrm{hl}=\mathrm{en} \& a \mathrm{~s}_{\text {_sdt }}=0,5$ (accessed 11 December 2018). https://doi.org/10.2139/ssrn.3096056

Bilous, F.R. and R.M. Krauss. 1988. Dominance and accommodation in the conversational behaviours of same-and mixed-gender dyads. Language and Communication 8(3/4): 183-194. https://doi.org/10.1016/0271-5309(88)90016-X

Blair-Loy, M., L.E. Rogers, D. Glaser, Y.L. Wong, D. Abraham and P.C. Cosman. 2017. Gender in engineering departments: Are there gender differences in interruptions of academic job talks? Social Sciences 6(1): 29-47. https://doi.org/10.3390/ socsci6010029

Coates, J. 2004. Women, men, and language: A sociolinguistic account of gender differences in language. 3rd ed. London: Pearson Longman.

2011. Gossip revisited: Language in all-female groups. In Language and gender: A reader, eds. J. Coates and P. Pichler, 199-223. United Kingdom: Wiley Blackwell.

Drew, P. 2014. Conversation analysis in sociolinguistics. In Research methods in sociolinguistics: A practical guide, eds. J. Holmes and K. Hazen, 9230-9246. New Jersey: John Wiley \& Sons.

Fishman, P. 1980. Conversational insecurity. In Language: Social psychological perspectives, eds. H. Giles, P. Robinson and P.M. Smith, 127-132. Oxford: Pergamon.

1983. Interaction: The work women do. In Language, gender, and society, eds.

B. Thorne, C. Kramarae and N. Henley, 89-101. Rowley, MA: Newbury House.

Franks, P. and K.D. Bertakis. 2003. Physician gender, patient gender, and primary care. Journal of Women's Health 12(1): 73-80. https://doi.org/10.1089/ 154099903321154167

Fritzsche, K., C. Abbo, G. Frahm and S.D. Monsalve. 2014. The doctor-patient relationship. In Psychosomatic medicine: An international primer for the primary care setting, eds. K. Fritzche, S.H. McDaniel and M. Wirsching, 25-32. NY: Springer Science \& Business Media. https://doi.org/10.1007/978-1-4614-1022-5_5

Hall, J., J. Irish, D.L. Roter, C. Ehrlich and L. Miller. 1994. Gender in medical encounters: An analysis of physician and patient communication in a primary care setting. Health Psychology 13(5): 384-392. https://doi.org/10.1037/0278-6133.13.5.384

Heritage, J. and D.W. Maynard. 2006. Communication in medical care: Interaction between primary care physicians and patients. Cambridge: University Press. https://doi.org/10.1017/CBO9780511607172 
Heritage, J. and S. Sefi. 1992. Dilemmas of advice: Aspects of the delivery and reception of advice in interactions between health visitors and first-time mothers. In Talk at work: Interaction in institutional settings, eds. P. Drew and J. Heritage, 359-417. Cambridge: Cambridge University Press.

Herring, S.D., D.A. Johnson and T. DiBenedetto. 2011. Participation in electronic discourse in a "feminist" field. In Language and gender: A reader, eds. J. Coates and P. Pichler, 171-182. United Kingdom: Wiley Blackwell.

Holmes, J. 2008. An Introduction to sociolinguistics. 3rd ed. United Kingdom: Pearson Longman.

James, D. and S. Clarke. 1993. Women, men, and interruptions: A critical review. In Gender and Conversational Interaction, ed. D. Tannen, 231-280. Oxford: Oxford University Press.

Kaplan, S.H., B. Gandek, S. Greenfield, W. Rogers and J. Ware. 1995. Patient and visit characteristics related to physicians' participatory decision-making style: Results from the medical outcomes study. Medical Care 33: 1176-1187. https://doi .org/10.1097/00005650-199512000-00002

Leet-Pellegrini, H.M. 1980. Conversational dominance as a function of gender and expertise. In Language social psychological perspectives, eds. H. Giles, P. Robinson and P.M. Smith, 97-104. Oxford: Pergamon Press.

Li, H.Z., M. Krysko, N.G. Desroches and G. Deagle. 2004. Reconceptualizing interruptions in physician-patient interviews: Cooperative and intrusive. Communication \& Medicine 1(2): 145-157. https://doi.org/10.1515/come.2004.1.2.145

Litosseliti, L. 2014. Gender and language theory and practice. New York: Routledge. https://doi.org/10.4324/9780203784792

Maltz, D. and R. Borker. 2011. A cultural approach to male-female miscommunication. In Language and gender: A reader, eds. J. Coates and P. Pichler, 487-502. United Kingdom: Wiley Blackwell.

Mohajer, L. 2006. Power and solidarity in conversations of Iranian women. PhD diss., Faculty of Languages and Linguistics, Universiti Malaya.

Peräkylä, A. 2002. Agency and authority: Extended responses to diagnostic statements in primary care encounters. Research on Language and Social Interaction 35(2): 219-247. https://doi.org/10.1207/S15327973RLSI3502_5

Peterson, C. 1986. Sex differences in conversational interruptions by preschoolers. Journal of the Atlantic Provinces Linguistic Association 8: 23-28.

Sacks, H., E.A. Schegloff and G. Jefferson. 1974. A simplest systematics for the organization of turn-taking for conversation. Language 50: 696-735. https://doi .org/10.1353/lan.1974.0010

Street Jr, R.L. and T.L. Murphy. 1987. Interpersonal orientation and speech behavior. Communications Monographs 54(1): 42-62. https://doi.org/10.1080/ 03637758709390215

Tannen, D. 1994. Gender and discourse. New York: Oxford University Press. 2005. Conversational style: Analyzing talk among friends. New York: Oxford University Press. 
Tates, K., M.L. Antheunis, S. Kanters, T.E. Nieboer and M.B. Gerritse. 2017. The effect of screen-to-screen versus face-to-face consultation on doctor-patient communication: An experimental study with simulated patients. Journal of Medical Internet Research 19(12): e421. https://doi.org/10.2196/jmir.8033

West, C. 2011. When the doctor is a "lady": Power, status and gender in physician-patient encounters. In Language and gender: A reader, eds. J. Coates and P. Pichler, 193-197. United Kingdom: Wiley Blackwell. 1998. "Not just doctors' orders": Directive-response sequence in patients' visits to women and men physicians. In Language and gender: A reader, ed. J. Coates, 328-353. United Kingdom: Wiley Blackwell.

Willes, K. and K. Allen. 2014. The importance of sexual orientation disclosure to physicians for women who have sex with women. In Health care disparities and the LGBT population, eds. V.L. Harvey and T.H. Housel, 9-26. United Kingdom: Lexington Books.

Zhao, X. and W. Gantz. 2003. Disruptive and cooperative interruptions in primetime television fiction: The role of gender, status, and topic. Journal of Communication 53(2): 347-362. https://doi.org/10.1111/j.1460-2466.2003 .tb02595.x

Zimmerman, D.H. and C. West. 1975. Sex roles, interruptions and silences in conversation. In Language and sex: Difference and dominance, eds. B. Throne and N. Henley, 105-129. Rowley, MA: Newbury House. 